\title{
Male-to-female excess in diabetes diagnosed in early adulthood is not specific for the immune-mediated form nor is it HLA-DQ restricted: possible relation to increased body mass index
}

\author{
I. Weets ${ }^{1}$, J. Van Autreve ${ }^{1}$, B.J. Van der Auwera ${ }^{1}$, F. C. Schuit ${ }^{1}$, M. V.L. Du Caju ${ }^{2}$, K. Decochez ${ }^{1}$, I.H.De Leeuw ${ }^{3}$, \\ B. Keymeulen ${ }^{1}$, C.Mathieu ${ }^{4}$, R. Rottiers ${ }^{5}$, H. Dorchy ${ }^{6}$, E. Quartier ${ }^{1}$, F. K. Gorus ${ }^{1}$ and the Belgian Diabetes Registry $^{7}$ \\ ${ }^{1}$ Diabetes Research Center, Free University, Brussels, Belgium \\ ${ }^{2}$ Department of Pediatrics, University of Antwerp, Antwerp, Belgium \\ ${ }^{3}$ Department of Endocrinology, University of Antwerp, Antwerp, Belgium \\ ${ }^{4}$ Department of Endocrinology, Catholic University, Leuven, Belgium \\ ${ }^{5}$ Department of Endocrinology, University of Ghent, Ghent, Belgium \\ ${ }^{6}$ Department of Diabetology, Children's University Hospital Queen Fabeola, Brussels, Belgium \\ ${ }^{7}$ Belgian Diabetes Registry, Brussels, Belgium
}

\section{Abstract}

Aims/hypothesis. We investigated whether the reported $H L A-D Q / D R$ restricted male-to-female (M:F) excess in Type I (insulin-dependent) diabetes mellitus also exists in Belgian patients, is specific for immune-mediated diabetes, remains genotype-restricted after adjustment for age at diagnosis, and is associated with sex-dependent environmental factors.

Methods. Autoantibodies, HLA-DQ and 5' INS (5'insulin gene) polymorphisms were assessed in 2532 diabetic patients (all phenotypes) diagnosed under 40 years of age. Autoantibodies and body mass index (expressed as a standard deviation score by comparison to age-matched and sex-matched control subjects; SDS-BMI) were measured in 1986 siblings or offspring of Type I diabetes patients (0-39 years).

Results. In patients aged 15-39 years at diagnosis, the male-to-female ratio was 1.5 or more regardless of their antibody status and significantly higher $(p<0.001)$ than that in the age-matched Belgian general population. There was no sex bias in patients under 15 years of age. Overall, the male-to-female ratio was significantly higher in patients without $H L A$ $D Q A 1 * 0301-D Q B 1 * 0302(p \leq 0.003)$ but stratifica- tion in age groups and multivariate analysis identified age as the major determinant of male-to-female ratio. The SDS-BMI increased $(p<0.01)$ in male antibodypositive relatives $(n=103)$ but not in female antibody-positive $(\mathrm{n}=92)$ or in antibody-negative relatives $(\mathrm{n}=1791)$. This phenomenon tended to be restricted to male relatives who were positive only for glutamate decarboxylase antibodies $(n=44)$.

Conclusions/interpretation. The male-to-female excess in Belgian diabetic patients diagnosed in early adulthood is not specific for immune-mediated Type I diabetes and not $H L A-D Q$ or 5'INS restricted. Our data suggest that, similar to Type II (non-insulin-dependent) diabetes mellitus, the metabolic burden of obesity and insulin resistance could preferentially precipitate postpubertal clinical onset in male subjects with slowly progressive subclinical (immune-mediated) diabetes. [Diabetologia (2001) 44: 40-47]

Keywords Diabetes, sex, autoantibodies, islet cell cytoplasmic antibodies, glutamate decarboxylase antibodies, IA-2 antibodies, $H L A-D Q$ genotype, insulin gene polymorphisms, $\mathrm{X}$ chromosome, body mass index.
Received: 12 July 2000 and in revised form: 24 August 2000

Corresponding author: F.K. Gorus, MD, PhD, Diabetes Research Center, Vrije Universiteit Brussel, Laarbeeklaan 103, B-1090 Brussels, Belgium

Abbreviations: M:F, Male-to-female; ICA, islet cell cytoplasmic antibodies; GADA, glutamate decarboxylase antibodies; IA-2-A, IA-2 antibodies; 5' INS, 5' insulin gene polymorphism; INS, insulin gene; VNTR, variable number of tandem repeats; BDR, Belgian Diabetes Registry; JDFU, Juvenile Diabetes Foundation Units; NDDG, National Diabetes Data Group.
The pathologic process underlying Type I diabetes is believed to be driven by the interplay of environmental triggers that are largely not known and multiple genetic factors that have been partly identified [1-6]. $H L A$ genes play a major part in genetic susceptibility and protection, the highest risk being conferred by the heterozygous combination of the two most prominent risk haplotypes DR4-DQA1*0301-DQB1*0302 and DR3-DQA1*0501-DQB1*0201 [1, 2, 5]. The role of the variable number of tandem repeats 


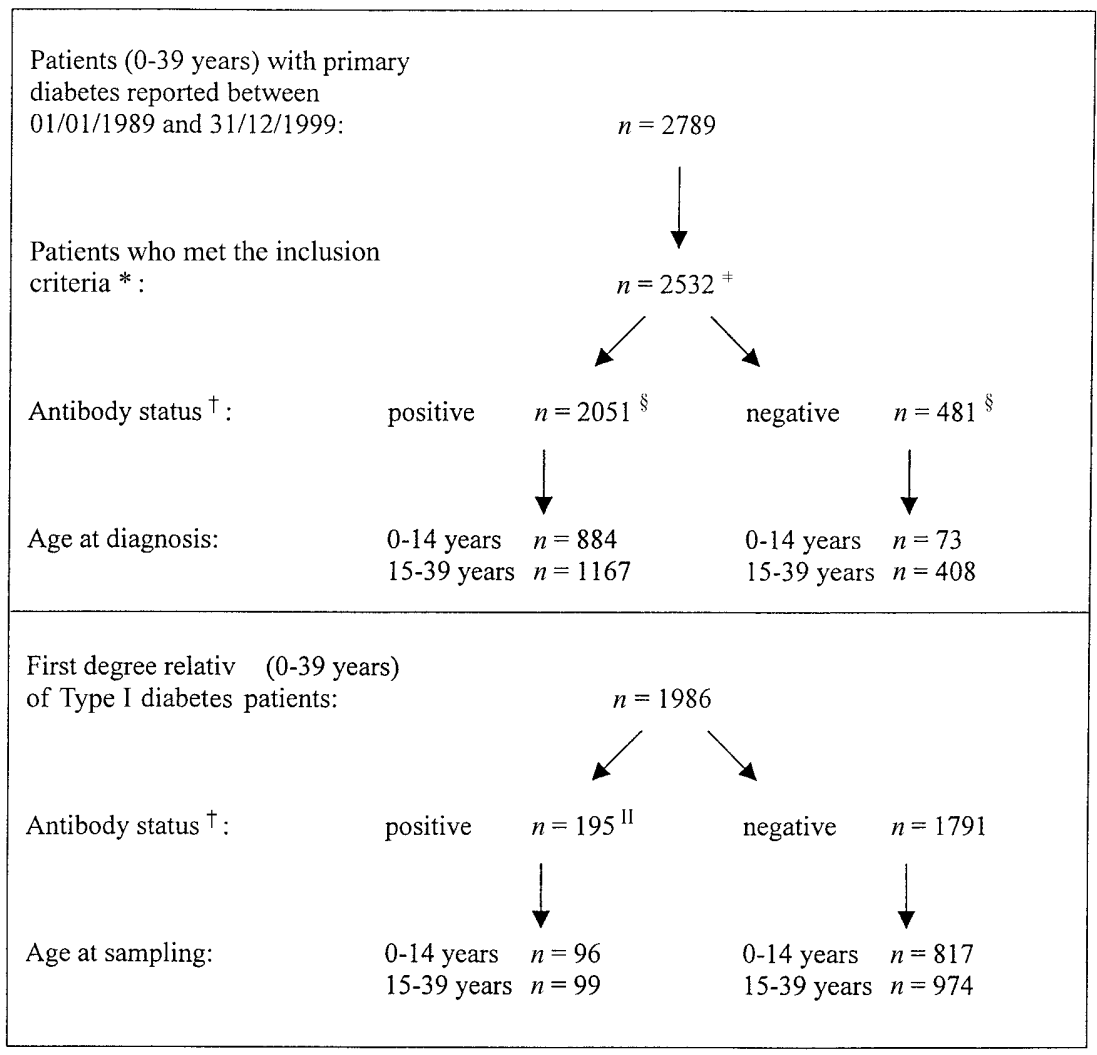

Fig. 1. Number of diabetic patients and first degree relatives according to antibody status and age at diagnosis or at sampling. * Caucasian ethnicity; availability of demographic data and blood samples for DNA and autoantibody analysis within 18 months after diagnosis; Belgian residency for at least 6 months before diagnosis. ${ }^{*}$ For 2371 of the 2532 included patients $(94 \%)$ a standard questionnaire was available with epidemiological, clinical and locally determined biological data. † Positivity for ICA, GADA or IA-2A; negativity for ICA, GADA and IA-2A. ${ }^{\S} n=1040$ sampled $0-7$ days after diagnosis. ${ }^{\text {II }} n=88$ positive for GADA alone; $n=107$ positive for ICA or IA-2A with or without GADA

(VNTR) in the 5' flanking region of the insulin gene $\left(5^{\prime} I N S\right)$ has been the best documented of the proposed non-HLA loci [2, 7-9]. Homozygosity for shorter class I alleles confers a moderate but significant risk, whereas the presence of at least one larger class III allele has a protective effect [9].

In view of the observed male-to-female (M:F) excess in Type I diabetic patients [5, 10-12], it is noteworthy that one of the diabetes susceptibility regions has been mapped to the X chromosome [2]. Recently, it has been reported that this male excess was limited to DR3-positive Type I diabetic patients without $D R 4$, suggesting that two distinct genetic pathways exist for diabetes: a $D R 4$-driven pathway and an alternative pathway involving the interaction of $D R 3$ with a putative $X$-linked genetic factor $[13,14]$.

The frequency of $H L A-D R$ or $D Q$ susceptibility alleles and the M:F ratio have been reported to vary according to age at clinical presentation $[5,10-12$, 15-17]. The differences observed in M:F ratio according to $H L A$ class II phenotype or genotype should, therefore, be investigated, to see whether they could derive from incomplete age-matching between these patient groups. The extent to which the M:F excess is restricted to Type I diabetes or can be observed in other forms of diabetes arising in childhood or early adulthood is also not known.

The aims of our study were therefore: (1) to confirm the existence of an age-dependent $M: F$ excess in a large representative group of autoantibody-positive Belgian Type I diabetic patients under 40 years of age at diagnosis and recruited nationwide over a period of more than 10 years; (2) to investigate whether this excess is specific to immune-mediated Type I diabetes by comparing antibody-positive and antibody-negative patients with diabetes and by reassessing the interaction of gender with $H L A-D Q$ and 5'INS genotypes in patients with diabetes after proper stratification for age at diagnosis; (3) in the absence of such interactions, to search for gender-dependent environmental factors associated with (the risk for) diabetes manifestations in early adulthood.

\section{Subjects and methods}

Subjects. Between 1 January 1989 and 31 December 1999, 2789 patients aged 0-39 years at diagnosis (all types of primary diabetes) were consecutively recruited by the Belgian Diabetes 
Table 1. Comparison of baseline characteristics in diabetic patients according to antibody status

\begin{tabular}{|c|c|c|c|}
\hline Baseline characteristics & $\begin{array}{l}\text { Antibody-positive patients* } \\
(n=2051)\end{array}$ & $\begin{array}{l}\text { Antibody-negative patients }{ }^{\neq} \\
(n=481)\end{array}$ & \\
\hline Age at diagnosis; years ${ }^{\dagger}$ & $17(10-27)$ & $30(20-35)$ & $<0.001$ \\
\hline Presence of $\geq 1$ symptom $^{\S}$ & $1838 / 1915(96)$ & $368 / 432(85)$ & $<0.001$ \\
\hline Duration of symptoms ${ }^{\S}$; weeks ${ }^{\dagger}$ & $3(2-8)$ & $4(2-12)$ & $<0.001$ \\
\hline Ketonuria & $1240 / 1583(78)$ & $170 / 342(50)$ & $<0.001$ \\
\hline Body mass index; $\mathrm{kg} / \mathrm{m}^{2 \dagger}$ & $19(16-22)$ & $24(21-30)$ & $<0.001$ \\
\hline Daily insulin dose after stabilisation; $\mathrm{U} / \mathrm{kg}^{\dagger}$ & $0.57(0.36-0.82)$ & $0.33(0.03-0.55)$ & $<0.001$ \\
\hline
\end{tabular}

Registry (BDR) through voluntary reporting by paediatricians and endocrinologists. Diabetes was diagnosed using the criteria of the National Diabetes Data Group [18]. Comparison with a subregion (the Antwerp district) with near complete case ascertainment ( $94 \%$ ) has shown that the larger group of patients recruited nationwide, with incomplete ascertainment (presently $55 \%$ ), is representative of Belgian diabetic patients diagnosed before 40 years of age [11]. Of the 2789 patients, 2532 who met the following criteria were included : (1) Caucasian ethnicity ( $97 \%$ of the subjects); (2) availability of demographic data and samples for centralised DNA and autoantibody analysis taken within the first 18 months after diagnosis; (3) Belgian residency for at least 6 months before diagnosis. A standard questionnaire with epidemiological, clinical, demographic and locally determined biological data was available for 2371 of the 2532 included patients $(94 \%)$ ). The 2532 patients were stratified according to the presence (immune-mediated Type I diabetic patients) or the absence (patients without evidence of immune-mediated Type I diabetes) of autoantibodies between 0 and 18 months after diagnosis [19]. A total of 2051 patients $(81 \%)$ showed positivity for at least one or more types of autoantibodies (islet cell antibodies, ICA; GAD65 antibodies, GADA; IA-2 antibodies, IA-2A) and 481 patients were negative for all three types of antibodies (19\%) (Fig. 1). On the basis of clinical findings, the latter subjects were classified by physicians into groups having Type I diabetes $(58 \%)$, Type II diabetes $(33 \%)$ or other forms of diabetes (9\%). Antibody-negative patients were on average older, had a lower prevalence of clinical symptoms and a longer prodromal phase, were less ketosis-prone and were more obese, and had higher random C-peptide levels and lower daily insulin needs than antibody-positive patients (Table 1).

Blood samples and data on height and weight were available at diagnosis (i.e. within 7 days after start of the insulin treatment) for 1040 antibody-positive patients. We used a large scale screening programme for first-degree relatives of Type I diabetic patients [20] to obtain blood samples and data on height and weight of relatives aged 0-39 years (antibody-negative siblings or offspring: $n=1791$; antibody-positive siblings or offspring: $n=195$ ) (Fig. 1). Body mass index (BMI) was analysed after being transformed into a standard deviation score (SDS) for comparison with data from a reference cohort comprising 15636 male and 14899 female subjects recruited between 1978 and 1990 [21]. This cohort was considered representative for the Belgian population because its growth and BMI charts correspond well with similar data derived from a smaller Brussels' cohort [22]. We preferred, however, the data from the reference cohort [21] because they are more recent and because the mean and standard deviations, available for each age group, allowed BMI to be expressed as SDS. The number of male and female subjects in the Belgian population under 40 years of age in the period between 1989 and 1999 was obtained from the Belgian National Institute for Statistics (Jaarlijkse Bevolkingsstatistieken, Annual Population Statistics, National Institute of Statistics, Brussels 1989-1999) and expressed as mean values for the study period.

The study was approved by the ethics committees of the universities participating in the scientific projects of the Belgian Diabetes Registry. Informed consent was obtained from each subject or their parents in accordance with the Helsinki Declaration.

Genetic analysis. DNA was extracted from potassium ethylenediaminetetraacetate-blood. The second exons of the $H L A-D Q A 1$ and $D Q B 1$ genes were simultaneously amplified by polymerase chain reaction [23], dot blotted on nylon membranes, fixed by ultraviolet irradiation, and hybridised to a panel of 15 different allele-specific oligonucleotide probes. Probe binding was made visible using chemiluminiscent detection methods [24]. The variable number tandem repeats (VNTR) polymorphism upstream from the insulin gene (INS) transcription initiation site $\left(5^{\prime}\right.$ INS ) was investigated by assessing a diallelic $\mathrm{A} / \mathrm{T}$ polymorphism at position -23 of the INS gene which is in nearly complete linkage disequilibrium with the 5'INS VNTR. Genotypes were determined by conventional PCR restriction fragment length polymorphism (PCRRFLP) analysis with restriction enzyme HphI (Amersham Pharmacia Biotech, Uppsala, Sweden) [24] or by a 5' nuclease $\left(\right.$ TaqMan $\left.^{\circledR}\right)$ assay with fluorogenic probes [25] on the ABI PRISM 7700 Sequence Detection System (PE Biosystems, Foster City, Calif., USA).

Antibody assays. We measured ICA using indirect immunofluorescence and endpoint titres expressed as Juvenile Diabetes Foundation (JDF) units [17]. We measured IA-2A and GADA by liquid-phase radiobinding assays as described previously and expressed as \% tracer bound [27]. Cut-off values for antibody positivity were defined as on the $99^{\text {th }}$ centile of the antibody concentrations obtained in 789 non-diabetic control subjects after omitting outlying values, and amounted to 12 JDF units or more for ICA (corresponding to a serum dilution of $1 / 20), 2.6 \%$ or more for GADA and $0.4 \%$ or more for IA-2A [28]. The antibody assays performed well in external quality control programmes (Immunology of Diabetes Workshops, Proficiency testing of the University of Florida, Gainesville, Fla., USA, and of the Louisiana State University, New 
Table 2. Male-to-female (M:F) ratio in autoantibody-positive (ICA, IA-2A and/or GADA) diabetic patients $(n=2051)$ diagnosed before age 40 years, recruited between 1 January 1989 and 31 December 1999 and stratified according to HLA$D Q$ genotype

\begin{tabular}{lll}
\hline HLA DQA1*-DQB1* & $\begin{array}{l}\mathrm{M} / \mathrm{F} \\
\mathrm{n} / \mathrm{n} \text { (ratio) }\end{array}$ & $p^{*}$ \\
\hline 0301-0302/0501-0201 & $324 / 270(1.20)$ & 0.100 \\
0301-0302/non $(0501-0201)$ & $334 / 276(1.21)$ & 0.077 \\
non(0301-0302)/0501-0201 & $345 / 248(1.39)$ & $<0.001$ \\
$\quad$ 0501-0201/0501-0201 & $113 / 77(1.47)$ & 0.025 \\
0501-0201/non $(0501-0201)$ & & \\
$\quad$ non $(0301-0302)$ & $232 / 171(1.36)$ & 0.011 \\
non $(0301-0302) / \operatorname{non}(0501-0201)$ & $154 / 100(1.54)$ & 0.003
\end{tabular}

* $p$ value vs $\mathrm{M}: \mathrm{F}=2,801,476 / 2,682,209$ (1.04) (mean value for Belgian population under age 40 years in the period 1989-1999; source Belgian National Institut of Statistics") by $\chi^{2}$ test; threshold for significance: $p<0.05 / 6$ or $p<0.008$ (Bonferroni adjustment)

Orleans, La., USA). Our three assays achieved $100 \%$ diagnostic sensitivity, specificity, consistency and validity in the latter programme. In the combinatorial islet autoantibody workshop [29] assay sensitivity adjusted for $99 \%$ specificity amounted to $73 \%$ for ICA, and $85 \%$ for GADA (IA-2A was not available in our laboratory at the time of the workshop, 1995).

Statistical analysis. Differences in the distribution of continuous variables between the groups were assessed using the Mann-Whitney U test or the Kruskal Wallis test and differences in the prevalences by using the chi-squared test ( $\chi^{2}$ test) with Yates' correction or Fisher's exact test as appropriate. To check if mean SDS were other than zero, we used a one-sample $t$ test. Stepwise forward logistic regression was used for multivariate analysis. All statistical tests were carried out two-tailed using SPSS for Windows 10.0 (SPSS, Chicago, Ill., USA) for personal computers and were considered significant at $p<0.05$ or, for $k$ independent tests, at $p<0.05 / k$ (Bonferroni correction) [30].

\section{Results}

M:F ratio according to $H L A-D Q$ genotype in patients with immune-mediated Type I diabetes. When all 2051 antibody-positive patients were stratified according to the presence or absence of $H L A-D Q A 1 *$ $D Q B 1^{*}$ risk haplotypes 0301-0302 and 0501-0201 (Table 2), the M:F ratio was found to be significantly higher in patients lacking 0301-0302 but not in subjects carrying 0301-0302 (Table 2) than in the agematched Belgian population. The various genotype groups, however, differed in age ( $p<0.001$ by Kruskal-Wallis test). The median age was lowest for the 0301-0302/0501-0201 group (15.9 years) and highest for the non(0301-0302)/non0501-0201) group (21.4 years).

M:F ratio at diagnosis of immune-mediated Type I diabetes according to age. In subjects under 15 years of age $(n=884)$, the M:F ratio approximated 1.1 ( $p>0.05$ vs the background population) but averaged 1.5 in the age group $15-39$ years $(n=1167 ; p=0.001$ vs age group 0-14 years) except for the patients aged 30-34 years (Table 3 ). When the latter category was pooled with the even smaller group of subjects aged 35-39 years, the M:F ratio averaged $1.45(p<0.002$ vs background population). Patients were therefore studied after stratification in two age groups (0-14 years and 15-39) years and by multivariate analysis with age as a continuous variable.

M:F ratio according to autoantibody status. The M:F ratio was not different from the value in the Belgian population in the age group 0-14 years for antibodypositive and for antibody-negative patients, but was significantly higher in the age group 15-39 years (Table 4). Regardless of the antibody status, age-matched male and female patients did not differ in severity of clinical presentation (number and duration of prodromal symptoms, presence of ketonuria), biological characteristics (random $\mathrm{C}$ peptide and glycaemia, \%

Table 3. Male-to-female (M:F) ratio in autoantibody-positive (ICA, IA-2A and/or GADA) diabetic patients $(n=2051)$ recruited between 1 January 1989 and 31 December 1999 and stratified according to age at clinical onset

\begin{tabular}{|c|c|c|c|c|c|}
\hline \multirow{3}{*}{$\begin{array}{l}\text { Age group } \\
\text { Years }\end{array}$} & \multicolumn{4}{|l|}{ M:F } & \multirow[t]{3}{*}{$p^{\ddagger}$} \\
\hline & \multicolumn{2}{|l|}{ Patients } & \multicolumn{2}{|c|}{ General population* } & \\
\hline & $n / n$ & (ratio) & $n / n$ & (ratio) & \\
\hline $5-9$ & $151 / 147$ & $(1.03)$ & $310,941 / 295,988$ & $(1.05)$ & 0.892 \\
\hline $10-14$ & 219/197 & (1.11) & $310,696 / 296,081$ & (1.05) & 0.590 \\
\hline $15-19$ & $156 / 105$ & (1.49) & $325,718 / 309,785$ & (1.05) & 0.007 \\
\hline $30-34$ & $122 / 102$ & $(1.20)$ & $405,158 / 391,283$ & (1.04) & 0.313 \\
\hline $35-39$ & $101 / 52$ & (1.94) & $397,461 / 377,647$ & $(1.05)$ & $<0.001$ \\
\hline
\end{tabular}

* mean value for the period 1989-1999 (source Belgian National Institute for Statistics); ${ }^{\ddagger} p$-value vs M:F ratio in age-matched general population by $\chi^{2}$ test; threshold for significance: $p<0.05 / 8$ or $p<0.006$ (Bonferroni adjustment) 
Table 4. Male-to-female (M:F) ratio in diabetic patients stratified according to age at clinical onset and to the presence or absence of autoantibodies (ICA, IA-2A and/or GADA)

\begin{tabular}{|c|c|c|c|c|c|c|}
\hline \multirow{3}{*}{$\begin{array}{l}\text { Age group } \\
\text { Years }\end{array}$} & \multicolumn{3}{|c|}{$\begin{array}{l}\text { Autoantibody-positive } \\
(\mathrm{n}=2051)\end{array}$} & \multicolumn{3}{|c|}{$\begin{array}{l}\text { Autoantibody-negative } \\
(\mathrm{n}=481)\end{array}$} \\
\hline & \multicolumn{2}{|l|}{ M:F } & \multirow[t]{2}{*}{$p^{*}$} & \multicolumn{2}{|l|}{$\mathrm{M}: \mathrm{F}$} & \multirow[t]{2}{*}{$\mathrm{p}^{*}$} \\
\hline & $n / n$ & (ratio) & & $n / n$ & (ratio) & \\
\hline $0-14$ & $461 / 423$ & (1.09) & 0.599 & $41 / 32$ & $(1.28)$ & 0.284 \\
\hline $15-39$ & $696 / 471$ & (1.48) & $<10^{-6}$ & $264 / 144$ & $(1.83)$ & $<10^{-6}$ \\
\hline
\end{tabular}

* $p$-value vs mean M:F ratio in age-matched general population in the period 1989-1999 (0-14 years: 929,326/885,437 [1.05]; 15-39 years: 1,872,150/1,796,772 [1.04]; source Belgian National institute of statistics) by $\chi^{2}$ test; threshold for significance: $p<0.05 / 4$ or $p<0.012$ (Bonferroni adjustment)

$\mathrm{HbA}_{1 \mathrm{c}}$ ) or maintenance insulin dose (data not shown).

M:F ratio according to age and HLA-DQ or 5'INS genotype. Because the M:F ratio did not differ according to the status of diabetes-associated autoantibodies, we grouped autoantibody-positive and antibody-negative subjects for $H L A-D Q$ and 5'INS genotypes before stratification. Regardless of the $H L A-D Q$ or 5'INS genotype, the M:F ratio for patients under age 15 years was not significantly different from the value in the background population. However, there was a tendency toward male excess in two small groups, namely 0501-0201 homozygotes (significance lost after Bonferroni correction) and in patients lacking both 0301-0302 and 0501-0201 $H L A-D Q$ haplotypes (Table 5). After age 15 , the $\mathrm{M}: \mathrm{F}$ ratio was significantly increased in all genotype groups except in the relatively small 0301-0302/ 0501-0201 and 0501-0201/0501-0201 groups where only a trend was noted (Table 5). Similar results were observed when antibody-positive patients were studied separately (results not shown). Multivariate analysis confirmed that male predominance was strongly dependent on age $(\mathrm{R}=0.048 ; p=0.004)$ but after adjustment for age, no longer on the presence or absence of autoantibodies, $H L A-D Q$ haplotypes [0301-0302 vs non(0301-0302); 0501-0201 vs non(0501-0201)] or genotypes [combinations of 0301-0302 or non(0301-0302) with 0501-0201 or non(0501-0201) with 0501-0201/0501-0201 homozygotes as a separate group] or 5'INS genotypes.

Body mass index according to age and gender in autoantibody-positive patients and first degree relatives of Type I diabetic patients. Male antibody-positive patients had a higher BMI than female patients when diagnosed after 15 years of age [median (interquartile range): $21(19-23) \mathrm{kg} / \mathrm{m}^{2}$ vs $20(18-22) \mathrm{kg} / \mathrm{m}^{2}$; $p<0.001]$ but not under 15 years of age (not shown). Similarly, both in the relatives (not shown) and in the reference cohort [21], men had a higher BMI than women after 15 years of age but not before. The BMI of patients at diagnosis was significantly lower, however, than that of control subjects (not shown) when expressed as an age-adjusted and sexadjusted SDS for comparison with a reference cohort [21].

Antibody-positive male relatives under 40 years of age had a significantly higher BMI than the reference cohort matched with them for age and sex (Table 6). The tendency to a higher BMI was observed in antibody-positive subjects under 15 years of age $(n=50)$ and above 15 years of age $(n=53)$ (not shown). The higher BMI in men who were antibody-positive relatives tended to be restricted to subjects with GADA but without ICA and IA-2A. It was not observed in

Table 5. Male-to-female (M:F) ratio in 2532 diabetic patients (autoantibody-positive and autoantibody-negative subjects) stratified according to age at clinical onset, $H L A-D Q$ and 5'INS genotype

\begin{tabular}{|c|c|c|c|c|c|c|}
\hline \multirow[t]{3}{*}{ Genotype } & \multicolumn{3}{|c|}{$0-14$ years $(n=957)$} & \multicolumn{3}{|c|}{$15-39$ years $(n=1575)$} \\
\hline & \multicolumn{2}{|l|}{$\overline{M: F}$} & \multirow[t]{2}{*}{$p^{*}$} & \multicolumn{2}{|l|}{$\mathrm{M}: \mathrm{F}$} & \multirow[t]{2}{*}{$p^{*}$} \\
\hline & $n / n$ & (ratio) & & $n / n$ & (ratio) & \\
\hline 0301-0302/0501-0201 & $165 / 154$ & $(1.07)$ & 0.898 & $179 / 132$ & $(1.36)$ & 0.025 \\
\hline $0301-0302 / \operatorname{non}(0501-0201)$ & $126 / 135$ & $(0.93)$ & 0.376 & $260 / 169$ & $(1.54)$ & $<10^{-4}$ \\
\hline $\operatorname{non}(0301-0302) / \operatorname{non}(0501-0201)$ & $60 / 43$ & $(1.39)$ & 0.183 & $237 / 142$ & $(1.67)$ & $<10^{-5}$ \\
\hline \multicolumn{7}{|l|}{$5^{\prime} I N S$} \\
\hline$I / I$ & $334 / 297$ & $(1.12)$ & 0.409 & $611 / 389$ & $(1.57)$ & $<10^{-6}$ \\
\hline I/III or III/III & $143 / 136$ & $(1.05)$ & 0.964 & $305 / 205$ & $(1.49)$ & $<10^{-4}$ \\
\hline
\end{tabular}

* $p$-value vs mean M:F ratio in age-matched general population in the period 1989-1999 (0-14 years: 929,326/885,437 [1.05]; 15-39 years: 1,872,150/1,796,772 [1.04]; source Belgian National Institute of Statistics) by $\chi^{2}$ test; threshold for significance: $p<0.05 / 16$ or $p<0.003$ (Bonferroni adjustment) 
Table 6. BMI of non-diabetic siblings or offspring of Type I diabetes patients expressed as a standard deviation score (SDS) in comparison to a reference cohort, after stratification for the presence or absence of diabetes-associated autoantibodies and gender

\begin{tabular}{|c|c|c|c|c|c|c|c|c|}
\hline \multirow[t]{2}{*}{ Sex } & \multicolumn{4}{|c|}{ Autoantibody-positive relatives* } & \multicolumn{4}{|c|}{ Autoantibody-negative relatives ${ }^{\ddagger}$} \\
\hline & $n$ & BMI & & $p^{\S}$ & $n$ & BMI & & $p^{\S}$ \\
\hline & & SDS & $(95 \% \mathrm{CI})^{\dagger}$ & & & SDS & $(95 \% \mathrm{CI})^{\dagger}$ & \\
\hline female & 92 & -0.10 & $(-0.39$ to 0.18$)$ & 0.480 & 896 & -0.06 & $(-0.14$ to 0.02$)$ & 0.118 \\
\hline
\end{tabular}

${ }^{*}$ positive for ICA, GADA and/or IA-2A, ${ }^{\ddagger}$ negative for ICA, GADA and IA-2A; ${ }^{\dagger} 95 \%$ confidence interval; ${ }^{\S}$ one sample $t$-test vs zero; threshold for significance: $p<0.05 / 4$ or $p<0.012$ (Bonferroni adjustment)

Table 7. BMI of antibody-positive nondiabetic siblings or offspring of Type I diabetic patients expressed as standard deviation score (SDS) in comparison to a reference cohort, after stratification according to sex and type of diabetes-associated autoantibodies

\begin{tabular}{llllll}
\hline Sex & Antibody type & $n$ & BMI & $p^{\ddagger}$ & \\
\hline \multirow{3}{*}{ Male } & & & SDS & $(95 \% \text { CI })^{*}$ & \\
& ICA and/or IA-2A & 59 & 0.18 & $(-0.14-0.50)$ & 0.260 \\
Female & GADA only & 44 & 0.62 & $(0.14-1.10)$ & 0.013 \\
& ICA and/or IA-2A & 48 & -0.05 & $(-0.38-0.29)$ & 0.782 \\
& GADA only & 44 & -0.16 & $(-0.65-0.33)$ & 0.505 \\
\hline
\end{tabular}

* 95\% confidence interval; ${ }^{\ddagger}$ one sample $t$-test: $p=0.010 \mathrm{vs}$ zero; threshold for significance: $p<0.05 / 4$ or $p<0.012$ (Bonferroni adjustment)

male relatives with any other combination of antibodies or in female relatives regardless of autoantibody (Table 7).

\section{Discussion}

A M:F excess has been reported in Type I diabetes patients $[5,10-12,31]$ in contrast to the female preponderance observed in most other autoimmune diseases [32]. Our study confirms previous reports that $\mathrm{M}: \mathrm{F}$ excess in Type I diabetes patients is confined largely to patients diagnosed after 15 years of age [5, 10-12, 31]. This M:F excess cannot be explained by a selection bias for several reasons: (1) it has also been observed in an epidemiological survey of Type I diabetes patients in the Antwerp area with near complete ascertainment [11], (2) a similar post-pubertal M:F excess has been observed in antibody-negative patients diagnosed after 15 years of age; (3) regardless of the presence of autoantibodies, men and women did not differ in terms of the severity of their inaugural clinical manifestations. In our study the M:F ratio approximated 1.1 in Type I patients diagnosed under the age of 15 , which agrees with the range observed throughout Europe (0.7 to 1.3) [10, 33, 34].

It has recently been reported [13] that the M:F excess observed in Caucasian Type I diabetic patients from the United States, United Kingdom and Sardinia and aged 0-29 years (mostly under 17 years of age) at diagnosis was restricted to HLA DR3-positive subjects lacking DR4 and provided evidence of a linkage between chromosome $\mathrm{Xp}$ and diabetes, a finding that could not be explained by transmissionratio distortion $[13,35]$. Male excess was most pronounced for DR3 homozygotes in Sardinia, which has the highest incidence of Type I diabetes together with Finland in the world $[33,34,36]$. Similar results were reported in Finnish children [14]. Our observations confirm a striking male preponderance of men among Type I diabetic patients without DR4$D Q A 1 * 0301-D Q B 1 * 0302$ when the age of diagnosis is not taken into account. After adjustment for age, however, the $\mathrm{M}: \mathrm{F}$ ratio no longer varied according to $H L A-D Q$ or 5'INS genotype. In childhood-onset diabetes, the highest M:F ratios were nevertheless observed in 0501-0201 homozygotes and subjects with neither 0501-0201 nor 0301-0302. These non-significant increases could provide further support, albeit weak, if confirmed in a larger group, to the proposed interaction of DR3-DQA1*0501-DQB1*0201 (or lack of DR4-DQA1*0301-DQB1*0302) with a putative $\mathrm{X}$-linked genetic factor as an alternative pathway for developing immune-mediated Type I diabetes, distinct from a DR4-DQA1*0301-DQB1*0302-driven pathway [13]. Because we genotyped a single nucleotide polymorphism and not the 5'INS VNTR our study cannot distinguish the differential effects of different class I alleles [9]. We did not assess the parental origin of class I alleles which is an essential feature of susceptibility/protection, due to a lack of DNA of relatives $[9,37]$. Altogether, our results indicate that the effect of age on the M:F ratio at clinical onset is much greater than the effect of $H L A$ or other genetic factors.

The post-pubertal M:F excess was observed both in antibody-positive and antibody-negative patients. It is possible that some Type I diabetic patients became antibody-negative before diagnosis, seroconverted to antibody-positivity later on, had immune markers not looked for by us or suffered from a nonimmune-mediated form of the disease [28, 38]. Overall, the antibody-negative patients had, however, more Type II-like features than the antibody-positive patients, indicating that the striking $M: F$ excess in adult-onset diabetes is not specific to Type I diabetes. 
We therefore wondered if increases in BMI, a prominent risk factor for Type II diabetes [19], could preferentially precipitate the clinical onset of diabetes in male subjects at risk. The analysis of BMI at diagnosis is not reliable because of the variable weight loss during the prodromal phase of the disease [19]. After diagnosis diet and treatment act as confounders [39]. Because the prediction of diabetes on a biological basis is still only possible for the immune-mediated form, we looked for a sex-specific association between increased BMI and early disease markers in first-degree relatives of Type I patients, who are a risk group for diabetes $[1,4,5]$.

Compared with the age-matched and sex-matched reference cohort [21] BMI was preferentially increased in male antibody-positive subjects, mostly with isolated GADA-positivity, a condition associated with a slow progression to diabetes $[1,5,27,40]$. It is possible, though not proven, that the higher metabolic demands of increased insulin resistance associated with puberty and increased BMI preferentially precipitate clinical onset in adolescent boys who are prone to diabetes after 15 years of age [41]. Animal studies have shown that higher metabolic activity is associated with increased GAD-expression in beta cells $[42,43]$. Our observations should be confirmed in longitudinal studies, preferably in different countries, but are in line with a Swedish study reporting an association between higher BMI, GADA and glucose-intolerance in middle-aged men and elderly women from a regional population [44]. The presence of IA-2A, ICA or multiple antibodies reflects a subclinical process that progresses more rapidly towards a clinical manifestation [1, 5, 27, 45-47]. It is noteworthy that in children who develop diabetes later (mean age at diagnosis: 8.3 years) weight gain increased during the first year of life compared with healthy siblings [48]. This growth pattern was weakly associated with the presence of IA-2A at diagnosis providing further evidence for a link between metabolic burden and immune-mediated beta-cell aggression, the character of which could vary according to the disease stage and intensity.

There is a considerable $\mathrm{M}: \mathrm{F}$ excess in diabetic patients aged 15-39 years, which is not specific for immune-mediated Type I diabetes or $H L A-D Q$ or 5'INS restricted. The association between higher BMI and GADA-positivity in male, but not in female, first-degree relatives suggests that, similar to Type II diabetes, the extra metabolic burden associated with puberty and greater BMI could preferentially precipitate progression of subclinical immune-mediated beta-cell aggression to clinical diabetes in male subjects.

Acknowledgements. We are grateful to D. Pipeleers, MD, PhD for helpful discussions and his generous support. Mrs L. Op De Beeck kindly provided the data file of the reference population used to calculate the SDS-values for height and BMI. The present work was supported by the Fund for Scientific Research Flanders (grant 3-0113-97 and Levenslijn-Diabetes project 7.0021.96) and by Bayer, Life Scan, Novo Nordisk, Ortho Clinical Diagnostics and Roche. The Belgian Diabetes Registry is supported financially by grants from the Ministries of Public Health of the Flemish and French communities. We would like to thank the Flemish Diabetes Association (VDV) and 175 physicians and members of the Belgian Diabetes Registry (whom we are regrettably unable to mention individually because of a request to limit the space from the editors) for their invaluable help in recruiting diabetic patients and first degree relatives and/or in the handling of blood samples or both. We are indebted to N. Alaerts, M. Bodson, N. Christophe, V. Claessens, A. Demarré, L. De Pree, S. Exterbille, T. Ghysels, P. Goubert, C. Groven, A. Ivens, D. Kesler, C. Lauwers, F. Lebleu, J. Michiels, H. Morobé, G. Schoonjans, H. Thomas, $\mathrm{K}$. Verbeeck and J. Vertommen for their excellent technical assistance. The JDF standard used to measure the ICA and the cDNA used to prepare ${ }^{35} \mathrm{~S}$-recombinant human GAD65 were donated by $\AA$. Lernmark MD, PhD (University of Washington, Seattle, USA) and by A. Falorni MD, PhD (when at the Karolinska Institute, Stockholm, Sweden). Human IA-2ic cDNA was a gift of M. Christie PhD (King's College School of Medicine and Dentistry, London, UK).

\section{References}

1. Slover RH, Eisenbarth GS (1997) Prevention of type 1 diabetes and recurrent $\beta$ cell destruction of transplanted islets. Endocr Rev 18: 241-258

2. Davies JL, Kawaguchi Y, Bennett ST et al. (1994) A genome wide search for human type 1 diabetes susceptibility genes. Nature 371: 130-136

3. Dahlquist G (1997) Viruses and other perinatal exposures as initiating events for $\beta$-cell destruction. Ann Med 29: 413-417

4. Leslie DR, Elliot RB (1994) Early environmental events as a cause of IDDM. Evidence and implications. Diabetes 43: 843-850

5. Gorus FK, the Belgian Diabetes Registry (1997) Diabetes registries and early biological markers of insulin-dependent diabetes mellitus. Diabetes Metab Rev 13: 247-274

6. Åkerblom HK, Knip M (1998) Putative environmental factors in type 1 diabetes. Diabetes Metab Rev 14: 31-67

7. Mein CA, Esposito L, Dunn MG et al. (1998) A search for type 1 diabetes susceptibility genes in families from the United Kingdom. Nature Genet 19: 297-300

8. Concannon P, Gogolin-Ewens KJ, Hinds DA et al. (1998) A second generation screen of the human genome for susceptibility to insulin-dependent diabetes mellitus. Nature Genet 19: 292-296

9. Bennet ST, Lucassen AM, Gough SC et al. (1995) Susceptibility to human type 1 diabetes at IDDM2 is determined by tandem repeat variation at the insulin gene minisatellite locus. Nature Genet 9: 284-292

10. Karvonen M, Pitkäniemi M, Pitkäniemi J, Kohtamäki K, Tajima N, Tuomilehto J for the World Health Organization DIAMOND Project Group (1997) Sex difference in the incidence of insulin-dependent diabetes mellitus: an analysis of the recent epidemiological data. Diabetes Metab Rev 13: 275-291

11. Vandewalle CL, Coeckelberghs MI, De Leeuw IH et al. (1997) Epidemiology, clinical aspects, and biology of IDDM patients under age 40 years. Diabetes Care 20: 1556-1561 
12. Östman J, Lernmark $\AA$, Landin-Olsson M et al. (1996) Autoimmune (type 1) diabetes in young adults in Sweden. Horm Metab Res 28: 348-350

13. Cucca F, Goy JV, Kawaguchi Y et al. (1998) A male-female bias in type 1 diabetes and linkage to chromosome Xp in MHC HLA-DR3-positive patients. Nature Genet 19: 301-302

14. Ilonen J, Knip M, Simell O (1998) HLA-DQA1*05$\mathrm{DQB} 1 * 02 / \mathrm{X}$ genotype is associated with an increased risk for IDDM in boys but not in girls. Diabetes 47 [Suppl]: A891 (Abstract)

15. Karjalainen J, Salmela P, Ilonen J, Surcel HM, Knip M (1989) A comparison of childhood and adult Type 1 diabetes mellitus. N Engl J Med 320: 881-886

16. Caillat-Zucman S, Garchon H-J, Timsit J et al. (1992) Agedependent HLA genetic heterogeneity of type 1 insulin-dependent diabetes mellitus. J Clin Invest 90: 2242-2250

17. Vandewalle CL, Decraene T, Schuit FC et al. (1993) Insulin autoantibodies and high titre islet cell antibodies are preferentially associated with the HLA DQA1*0301DQB*0302 haplotype at clinical onset of Type I (insulindependent) diabetes mellitus before age 10 years, but not at onset between age 10 and 40 years. Diabetologia 36: 1155-1162

18. National Diabetes Data Group (1979) Classification and diagnosis of diabetes mellitus and other categories of glucose intollerance. Diabetes 28: 1039-1057

19. The Expert Committee on the Diagnosis and Classification of Diabetes Mellitus (1997) Report of the Expert Committee on the Diagnosis and Classification of Diabetes Mellitus. Diabetes Care 20: 1183-1197

20. Gorus F (1996) Klinisch onderzoeksproject Levenslijn: Start van een Vlaams onderzoeksprogramma naar vroege diagnose en preventie van diabetes. Tijdschr Geneesk 52: 1133-1136

21. Cole TJ, Freeman JV, Preece MA (1995) Body mass index reference curves for the UK, 1990. Arch Dis Child 73: 25-29

22. Wachholder A, Hauspie RC (1986) Clinical standards for growth in height of belgian boys and girls, aged 2 to 18 years. Int J Anthropol 1: 327-338

23. Heimberg H, Nagy ZP, Somers G, De Leeuw I, Schuit FC (1992) Complementation of HLA-DQA and -DQB genes confers susceptibility and protection to insulin-dependent diabetes mellitus. Hum Immunol 320: 10-17

24. Van der Auwera BJ, Schuit FC, Lyaruu I et al. (1995) Genetic susceptibility for insulin-dependent diabetes mellitus in Caucasians revisited: the importance of diabetes registries in disclosing interactions between HLA-DQ- and insulin gene-linked risk. J Clin Endocrinol Metab 80: 2567-2573

25. Livak KJ, Marmaro J, Todd JA (1995) Towards fully automated genome-wide polymorphism screening. Nat Genet 9: 341-342

26. Gyapay G, Morissette J, Vignal A et al. (1994) The 1993-1994 Généthon human genetic linkage map. Nat Genet 7: 246-339

27. Gorus FK, Goubert P, Semakula C et al. (1997) IA-2-autoantibodies complement GAD65-autoantibodies in new-onset IDDM patients and help predict impending diabetes in their siblings. Diabetologia 40: 95-99

28. Decochez K, Tits J, Coolens J-L et al. (2000) High frequency of persisting or increasing islet-specific autoantibody levels after diagnosis of insulin-requiring type 1 diabetes presenting before age 40 years. Diabetes Care 23: 838-844

29. Verge CF, Stenger D, Bonifacio E et al. (1998) Combined use of autoantibodies (IA2ab, GADab, IAA, ICA): combinatorial islet autoantibody workshop. Diabetes 47: 1857-1866
30. Bland JM, Altman DG (1995) Multiple significance tests: the Bonferroni method. BMJ 310: 170

31. Bruno G, Merletti F, Vuolo A, Pisu E, Giorio M, Pagano G (1993) Sex differences in incidence of IDDM in age-group 15-29 yr. Diabetes Care 16: 133-136

32. Whitacre CC, Reingold SC, O'Looney PA, the Task force on Gender Multiple Sclerosis and Autoimmunity (1999) A gender gap in autoimmunity. Science 283: 1277-1278

33. Green A, Gale EAM, Patterson CC for the EURODIAB ACE Study Group (1992) Incidence of childhood-onset insulin-dependent diabetes mellitus: the EURODIAB ACE study. Lancet 339: 905-909

34. EURODIAB ACE Study Group (2000) Variation and trends in incidence of childhood diabetes in Europe. Lancet 355: 873-876

35. Zavattari P, Esposito L, Nutland S, Todd JA, Cucca F (2000) Transmission-ratio distortion at Xp11.4-p21.1 in type 1 diabetes. Am J Hum Genet 66: 330-332

36. Tuomilehto J, Karvonen M, Pitkäniemi J et al. (1999) Record-high incidence of Type I (insulin-dependent) diabetes mellitus in Finnish children. Diabetologia 42: 655-660

37. Bennett ST, Wilson AJ, Esposito L et al. (1997) Insulin VNTR allele-specific effect in type 1 diabetes depends upon identity of untransmitted parental allele. Nature Genet 17: 350-352

38. Imagawa A, Hanafusa T, Miyagawa J-I, Matsuzawa Y, Osaka IDDM Study Group (2000) A novel subtype of type 1 diabetes mellitus characterized by a rapid onset and an absence of diabetes-related antibodies. N Engl J Med 342: 301-307

39. Holl RW, Heinze E, Seifert M, Grabert M, Teller WM (1994) Longitudinal analysis of somatic development in paediatric patients with IDDM: genetic influences on height and weight. Diabetologia 37: 925-929

40. Wagner R, McNally JM, Bonifacio E et al. (1994) Lack of immunological changes in the islets of nondiabetic, autoimmune, polyendocrine patients with beta-selective GADspecific islet cell antibodies. Diabetes 43: 851-856

41. Leslie RD, Taylor R, Pozzilli P (1997) The role of insulin resistance in the natural history of type 1 diabetes. Diabet Med 14: 327-331

42. Björk E, Kämpe O, Andersson A, Karlson F (1992) Expression of the $64 \mathrm{kDa}$ glutamate acid decarboxylase rat islet cell autoantigen is influenced by the rate of insulin secretion. Diabetologia 35: 490-493

43. Degli Esposti M, Mackay IR (1997) The GABA network and the pathogenesis of IDDM. Diabetologia 40: 352-356

44. Rolandsson O, Hägg E, Hampe C et al. (1999) Glutamate decarboxylase (GAD65) and tyrosine phosphatase-like protein (IA-2) autoantibodies index in a regional population is related to glucose intolerance and body mass index. Diabetologia 42: 555-559

45. Kulmala P, Savola K, Petersen JS et al. (1996) Prediction of insulin-dependent diabetes mellitus in siblings of children with diabetes. A population-based study. The Childhood Diabetes in Finland Study Group. J Clin Invest 101:327-336

46. Verge CF, Gianani R, Kawasaki E et al. (1996) Prediction of type 1 diabetes in first degree relatives using a combination of insulin, glutamic acid decarboxylase and ICA 512 bdc/IA-2 autoantibodies. Diabetes 41: 926-933

47. Bonifacio E, Bingley PJ, Shattock M et al. (1990) Quantification of islet cell antibodies and prediction of insulin-dependent diabetes. Lancet 335: 147-149

48. Bruining GJ for the Netherlands Kolibrie study group of childhood diabetes (2000) Association between infant growth before onset of juvenile type-1 diabetes and autoantibodies to IA-2. Lancet 356: 655-656 